\title{
WEAK CONVERGENCE OF THE SIMPLE LINEAR RANK STATISTIC UNDER MIXING CONDITIONS IN THE NONSTATIONARY CASE*
}

\author{
M. HAREL ${ }^{\dagger}$ AND M. L. PURI ${ }^{\dagger \ddagger}$
}

\begin{abstract}
The asymptotic distribution theory of simple linear rank statistics for the case when the underlying random variables are nonstationary is studied both for the $\varphi$-mixing and strong mixing cases.
\end{abstract} mixing

Key words. weak convergence; linear rank statistics, empirical processes, $\varphi$-mixing, strong

1. Introduction. Let $X_{n i}, 1 \leqq i \leqq n, n \geqq 1$, be real-valued r.v.'s (random variables) with continuous d.f.'s (distribution functions) $F_{n i}(x), x \in \mathbf{R}$, and let $c_{n i}$ $(1 \leqq i \leqq n, n \geqq 1)$ be an array of regression constants defined by a function $g$ on $[0,1]$ as

$$
c_{n i}=g(i / n), \quad 1 \leqq i \leqq n, \quad n \geqq 1 .
$$

Denote by $\widehat{H}_{n}(x)=n^{-1} \sum_{i=1}^{n} c_{n i} \mathbf{1}_{\left[X_{n i} \leqq x\right]}$ the weighted empirical process where $\mathbf{1}_{[]}$ denotes the indicator function and by $\widehat{F}_{n}(x)=n^{-1} \sum_{i=1}^{n} \mathbf{1}_{\left[X_{n i} \leqq x\right]}$ the usual empirical process.

The corresponding expectations are denoted by

$$
H_{n}=\mathbf{E}\left(\widehat{H}_{n}\right) \text { and } F_{n}=\mathbf{E}\left(\widehat{F}_{n}\right) .
$$

We will study the asymptotic behavior of the simple linear rank statistic of the form

$$
\mathcal{S}_{n}(J)=n^{1 / 2} \int_{-\infty}^{+\infty} J\left(\frac{n}{n+1} \widehat{F}_{n}(x)\right) d \widehat{H}_{n}(x) \int_{-\infty}^{+\infty} J\left(F_{n}(x)\right) d H_{n}(x),
$$

where $J$ is a score function defined on the open unit interval.

The problem of finding a sufficiently large class of score functions for which the linear rank statistic is asymptotically normal was first considered by Chernoff and Savage [3]. Their results were later on strengthened considerably by several authors, mainly by Govindarajulu et al. [8], Pyke and Shorack [10], Hájek [9] and Dupač and Hájek [6] for the independent case, by Fears and Mehra [7] for the $\varphi$-mixing case with stationary random variables, and by Denker and Rösler [4] for the $\varphi$-mixing as well as strong mixing case but under a stationary set-up. In this paper we investigate the asymptotic distribution theory of the simple linear rank statistics (1.2) for the case when the underlying random variables are nonstationary.

2. Preliminaries. In this section, we give some propositions that are minor variations of Denker and Rösler [4] and so their proofs will be either omitted or briefly outlined.

*Received by the editors July $5,1990$.

†Department of Mathematics, Indiana University, Bloomington, Indiana 47405.

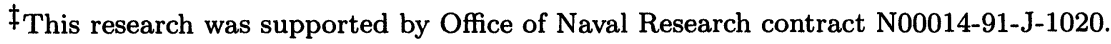


For $\delta \geqq 0$, set $\eta=\delta(4+2 \delta)^{-1}$.

Let $\mu_{\delta}$ denote the measure on $[0,1]$ given by its density $(z(1-z))^{-1 / 2-\eta}$ relative to the Lebesgue measure. For a monotone function $J$, let $\|J\|_{\delta}$ be the $\mathbf{L}_{1}$-norm of $J$ in $\mathbf{L}_{1}\left(\mu_{\delta}\right)$. By the Jordan decomposition of any right continuous function, $J$ has a unique decomposition: $J=J_{1}-J_{2}$ where $J_{1}$ and $J_{2}$ are monotone functions and $J_{1}\left(\frac{1}{2}\right)=0$. For such a function, we set

$$
\|J\|_{\delta}=\left\|J_{1}\right\|_{\delta}+\left\|J_{2}\right\|_{\delta}
$$

where $J_{1}$ and $J_{2}$ belong to $\mathbf{L}_{1}\left(\mu_{\delta}\right)$.

Denote by $\mathcal{H}_{\delta}$ the space of all right continuous functions $J$ with $\|J\|_{\delta}<\infty$ and $J\left(\frac{1}{2}\right)=0$ and let $\mathcal{G}_{\delta}$ be the set of all $J \in \mathcal{H}_{\delta}$ for which the measure $\nu$ defined by $J=\int d \nu$ is absolutely continuous with respect to Lebesgue measure. It is well known that $\mathcal{G}_{\delta}$ is the \|\|$_{\delta}$-norm closure of $\mathbf{C}_{2, b}$ : the space of functions with bounded second derivatives. The a priori assumption of having the space $\mathcal{H}_{\delta}$ of right continuous functions $J$ with $J\left(\frac{1}{2}\right)=0$ is no restriction because $\bar{J}$ defined by $\bar{J}(x)=J(x+)=$ $\lim _{y \downarrow x} J(y)$ is a well-defined right continuous function and if $\bar{J}$ belongs to $\mathcal{H}_{\delta}, \mathcal{S}_{n}(J)$ and $\mathcal{S}_{n}(\bar{J})$ are asymptotically equivalent (see [4]).

We consider the array $G_{n i}(1 \leqq i \leqq n, n \geqq 1)$ of d.f.'s on $[0,1]$ defined by

$$
G_{n i}=F_{n i} \circ F_{n}^{-1} \text {. }
$$

Denote by $\widehat{G}_{n}$ the empirical process in $[0,1]$ derived from $\widehat{H}_{n}$ and defined by

$$
\widehat{G}_{n}(t)=n^{-1} \sum_{i=1}^{n} c_{n i} \mathbf{1}_{\left[F_{n}\left(X_{n i}\right) \leqq t\right]}, \quad t \in[0,1],
$$

and $\hat{I}_{n}$ the empirical process on $[0,1]$ derived from $\widehat{F}_{n}$ and defined by

$$
\hat{I}_{n}(t)=n^{-1} \sum_{i=1}^{n} \mathbf{1}_{\left[F_{n}\left(X_{n i}\right) \leqq t\right]}, \quad t \in[0,1] .
$$

We also denote $G_{n}=\mathbf{E}\left(\widehat{G}_{n}\right)$ and $I_{n}=\mathbf{E}\left(\hat{I}_{n}\right)$. The linear rank statistic defined in (1.2) can then be written as

$$
\mathcal{S}_{n}(J)=n^{1 / 2} \int_{0}^{1} J\left(\frac{n}{n+1} \hat{I}_{n}(t)\right) d \widehat{G}_{n}(t)-n^{1 / 2} \int_{0}^{1} J\left(I_{n}(t)\right) d G_{n}(t) .
$$

The connection between the dependence structure of the processes and the class of functions for which asymptotic normality holds is expressed by the following condition:

$$
\left\{\begin{array}{l}
n \mathbf{E}\left(\widehat{G}_{n}(t)-G_{n}(t)\right)^{2} \leqq C \Lambda_{n}^{2}(t(1-t))^{1-2 \eta}, \\
n \mathbf{E}\left(\hat{I}_{n}(t)-I_{n}(t)\right)^{2} \leqq C(t(1-t))^{1-2 \eta}
\end{array}\right.
$$

for all $t \in(0,1)$ and $n \geqq 1$ where $\eta=\delta(4+2 \delta)^{-1}, \Lambda_{n}=\sup _{1 \leqq i \leqq n}|g(i / n)|$ for $g$ defined in (1.1) and $C$ is some positive constant.

Proposition 2.1. Let $K>0$ and $\delta \geqq 0$ be given. Then there exists a constant $C_{1}$ such that the following holds: if $\left\{X_{n i}\right\}$ is an array of r.v.'s satisfying (2.5) and if $\left\{c_{n i}\right\}$ are regression constants defined by (1.1), we have

$$
n \mathbf{E}\left\{\int_{-\infty}^{+\infty} J\left(\frac{n}{n+1} \widehat{F}_{n}(x)\right) d \widehat{H}_{n}(x)\right.
$$




$$
\begin{array}{r}
\left.-\int_{-\infty}^{+\infty} J\left(\frac{n}{n+1} F_{n}(x)\right) d \widehat{H}_{n}(x)\right\}^{2} \leqq C_{1} \Lambda_{n}^{2}\|J\|_{\delta}^{2}, \\
n \mathbf{E}\left\{\int_{-\infty}^{+\infty} J\left(\frac{n}{n+1} F_{n}(x)\right) d\left(\widehat{H}_{n}-H_{n}\right)(x)\right\}^{2} \leqq C_{1} \Lambda_{n}^{2}\|J\|_{\delta}^{2}, \\
n\left\{\int_{-\infty}^{+\infty}\left(J\left(F_{n}(x)\right)-J\left(\frac{n}{n+1} F_{n}(x)\right)\right) d H_{n}(x)\right\}^{2} \leqq C_{1} \Lambda_{n}^{2}\|J\|_{\delta}^{2}, \\
n \mathbf{E}\left(\mathcal{S}_{n}(J)\right)^{2} \leqq C_{1} \Lambda_{n}^{2}\|J\|_{\delta}^{2} .
\end{array}
$$

Proof. We only prove (2.6) because our method of proof is similar to that of Proposition 2 in [4]. It suffices to consider an increasing function $J \in \mathcal{H}_{\delta}$. Define

$$
\varphi(x, t)=\left\{\begin{aligned}
1 & \text { if } \frac{n}{n+1} F_{n}(x) \leqq t<\frac{n}{n+1} \widehat{F}_{n}(x), \\
-1 & \text { if } \frac{n}{n+1} \widehat{F}_{n}(x) \leqq t<\frac{n}{n+1} F_{n}(x) \\
0 & \text { otherwise }
\end{aligned}\right.
$$

and denote by $\widehat{F}_{n}^{-1}(t)=\inf \left\{x \in \mathbf{R}: \widehat{F}_{n}(x) \geqq t\right\}$ the left continuous inverse of $\widehat{F}_{n}$. Since for $t \leqq n /(n+1)$,

$$
\varphi(x, t)=\left\{\begin{aligned}
1 & \text { if } \quad \widehat{F}_{n}^{-1}\left(\frac{n+1}{n} t\right) \leqq x<F_{n}^{-1}\left(\frac{n+1}{n} t\right) \\
-1 & \text { if } \quad F_{n}^{-1}\left(\frac{n+1}{n} t\right) \leqq x<\widehat{F}_{n}^{-1}\left(\frac{n+1}{n} t\right) \\
0 & \text { otherwise }
\end{aligned}\right.
$$

it follows that for fixed $t \leqq n /(n+1)$,

$$
\begin{aligned}
& \left|\int_{-\infty}^{\infty} \varphi(x, t) d \widehat{H}_{n}(x)\right| \leqq \Lambda_{n} \int_{-\infty}^{\infty}|\varphi(x, t)| d \widehat{F}_{n}(x) \\
& \quad=\Lambda_{n}\left|\left\langle\frac{n+1}{n} t\right\rangle-\widehat{F}_{n}\left(F_{n}^{-1}\left(\frac{n+1}{n} t\right)-\right)\right| \\
& \quad \leqq \Lambda_{n}\left(\left|\widehat{F}_{n}\left(F_{n}^{-1}\left(\frac{n+1}{n} t\right)-\right)-\frac{n+1}{n} t\right|+2 \inf \{1 / n, t\}\right)
\end{aligned}
$$

where $\langle t\rangle=(k-1) / n$ if $(k-1) / n<t \leqq k / n$. that

From the assumption (2.5) on the sequence $\left\{X_{n i}\right\}$, it follows for $t \leqq n /(n+1)$

$$
\begin{aligned}
\left(\int_{-\infty}^{+\infty} \varphi(x, t) d \widehat{H}_{n}(x)\right)^{2} & \leqq 8 \Lambda_{n}^{2}\left(\frac{1}{n}(1 \wedge n t)\right)^{2}+2 \mathbf{E}\left(\hat{I}_{n}\left(\frac{n+1}{n} t\right)-I_{n}\left(\frac{n+1}{n} t\right)\right)^{2} \\
& \leqq 8 \Lambda_{n}^{2}\left(\frac{1}{n}(1 \wedge n t)\right)^{2}+2 \frac{C}{n} \Lambda_{n}^{2}(t(1-t))^{1-2 \eta}
\end{aligned}
$$

Finally, interchanging the order of integration, and using the Cauchy-Schwarz inequal- 
ity, we obtain

$$
\begin{gathered}
n \mathbf{E}\left(\int_{-\infty}^{+\infty} J\left(\frac{n}{n+1} \widehat{F}_{n}(x)\right) d \widehat{H}_{n}(x)-\int_{-\infty}^{+\infty} J\left(\frac{n}{n+1} F_{n}(x)\right) d \widehat{H}_{n}(x)\right)^{2} \\
=n \mathbf{E}\left(\int_{0}^{n /(n+1)} \int_{-\infty}^{+\infty} \varphi(x, t) d \widehat{H}_{n}(x) d J(t)\right)^{2} \\
\leqq n\left(\int_{0}^{n /(n+1)}\left(\mathbf{E}\left(\int_{-\infty}^{+\infty} \varphi(x, t) d \widehat{H}(x)\right)^{2}\right)^{1 / 2} d J(t)\right)^{2} \\
\leqq n C_{1} \Lambda_{n}^{2}\left(\int_{0}^{n /(n+1)} \frac{1}{n}(1 \wedge n t) d J(t)\right. \\
\left.\quad+\int_{0}^{n /(n+1)} n^{-1 / 2}(t(1-t))^{1 / 2-\eta} d J(t)\right)^{2} \leqq C_{1} \Lambda_{n}^{2}\|J\|_{\delta}^{2}
\end{gathered}
$$

where $C_{1}$ is some positive constant, since

$$
n^{1 / 2} \int_{0}^{n /(n+1)}(1 / n)(1 \wedge n t) d J(t) \leqq C_{1} \int_{0}^{1}(t(1-t))^{1 / 2} d J(t)
$$

The inequality $(2.6)$ is proved.

Proposition 2.2. Let $\left\{X_{n i}\right\}$ satisfy condition (2.5) for some $\delta>0$, and let the regression constants $c_{n i}$ satisfy (1.1) and $\sup _{n \in \mathbf{N}} \Lambda_{n}<+\infty$. Assume that $K \subset$ $\mathcal{H}_{\delta}$ is a subset possessing the following property: for every $J \in K$, there exists a normal distribution $\mathcal{N}\left(0, \sigma^{2}\right)$ where $0<\sigma<+\infty$ such that $\mathcal{S}_{n}(J)$ converges in law to $\mathcal{N}\left(0, \sigma^{2}\right)$, then the \|\|$_{\delta^{-} \text {norm }}$ closure of $K$ has the same property.

Proof. Let $J_{1} \in \bar{K}$ where $\bar{K}$ is the closure of $K$, and $J \in K$. By Proposition 2.1 and the fact that $\mathcal{S}_{n}\left(J_{1}\right)=\mathcal{S}_{n}(J)+\mathcal{S}_{n}\left(J_{1}-J\right)$, the distributions of $\mathcal{S}_{n}\left(J_{1}\right)$ and $\mathcal{S}_{n}(J)$ are closed, uniformly in $n$, in the weak topology for sufficiently small $\left\|J-J_{1}\right\|_{\delta}$. This proves the proposition.

For two probability measures $\mathbf{P}$ and $\mathbf{Q}$ on $\mathbf{R}$, denote by $D_{2}(\mathbf{P}, \mathbf{Q})=\inf (\mathbf{E}(X-$ $\left.Y)^{2}\right)^{1 / 2}$ where the infinitum extends over all r.v.'s $X$ and $Y$ defined on the same probability space and having distributions $\mathbf{P}$ and $\mathbf{Q}$, respectively.

Let $\mathcal{L}(Z)$ denote the distribution of the r.v. $Z$.

Proposition 2.3. Let $\left\{X_{n i}\right\}$ satisfy condition (2.5) for some $\delta>0$ and let $c_{n i}$ satisfy (1.1) and $\sup _{n \in \mathbf{N}^{*}} \Lambda_{n}<+\infty$. Assume that there exists an operator $\sigma: \mathcal{H}_{\delta} \rightarrow \mathbf{R}$ which is uniformly bounded and satisfies the Lipschitz condition for the \|\|$_{\delta}$ norm.

If for every $J \in K \subset \mathcal{H}_{\delta}, \mathcal{S}_{n}(J)$ converges in law to a normal distribution $\mathcal{N}\left(0, \sigma^{2}(J)\right)$, then the \|\|$_{\delta}$-norm closure of $K$ has the same property.

Proof. Let $J_{1} \in \bar{K}$ and $J \in K$. Then, we have

$$
\begin{aligned}
& D_{2}(\left.\mathcal{L}\left(\mathcal{S}_{n}\left(J_{1}\right)\right), \mathcal{N}\left(0, \sigma^{2}\left(J_{1}\right)\right)\right) \leqq D_{2}\left(\mathcal{L}\left(\mathcal{S}_{n}\left(J_{1}\right)\right), \mathcal{L}\left(\mathcal{S}_{n}(J)\right)\right) \\
& \quad+D_{2}\left(\mathcal{L}\left(\mathcal{S}_{n}(J)\right), \mathcal{N}\left(0, \sigma^{2}(J)\right)\right)+D_{2}\left(\mathcal{N}\left(0, \sigma^{2}(J)\right), \mathcal{N}\left(0, \sigma^{2}\left(J_{1}\right)\right)\right) \\
& \quad \leqq D_{2}\left(\mathcal{L}\left(\mathcal{S}_{n}(J)\right), \mathcal{N}\left(0, \sigma^{2}(J)\right)\right)+C^{\prime}\left\|J-J_{1}\right\|_{\delta}
\end{aligned}
$$

for some $C^{\prime}>0$ using Proposition 2.1 and the Lipschitz condition on $\sigma$.

Since the convergence in law from $\mathcal{S}_{n}(J)$ to $\mathcal{N}\left(0, \sigma^{2}(J)\right)$ implies (see [4])

$$
\lim _{n \rightarrow \infty} D_{2}\left(\mathcal{L}\left(\mathcal{S}_{n}(J)\right), \mathcal{N}\left(0, \sigma^{2}\left(J_{1}\right)\right)\right)=0
$$


the theorem follows.

3. Convergence of the linear rank statistic. Recall that the sequence $\left\{X_{n i}\right\}$ is $\varphi$-mixing if

$$
\begin{gathered}
\sup _{n \geqq 1} \sup _{1 \leqq j \leqq n-m}\left\{\operatorname { s u p } \left\{|\mathbf{P}(B \mid A)-\mathbf{P}(B)| ; A \in \sigma\left(X_{n i}, 1 \leqq i \leqq j\right),\right.\right. \\
\left.\left.B \in \sigma\left(X_{n i}, i \geqq j+m\right)\right\}\right\}=\varphi(m) \downarrow 0
\end{gathered}
$$

for positive integers $j$ and $m$.

Here $\sigma\left(X_{n 1}, \ldots, X_{n j}\right)$ and $\sigma\left(X_{n, j+m}, \ldots, X_{n n}\right)$ are the $\sigma$-fields generated by $\left(X_{n 1}, \ldots, X_{n j}\right)$ and $\left(X_{n, j+m}, \ldots, X_{n n}\right)$, respectively.

Also recall that $\left\{X_{n i}\right\}$ satisfies the strong mixing condition if

$$
\begin{gathered}
\sup _{n \geqq 1} \sup _{1 \leqq j \leqq n-m}\left\{\operatorname { s u p } \left\{|\mathbf{P}(A \cap B)-\mathbf{P}(A) \mathbf{P}(B)| ; A \in \sigma\left(X_{n i}, 1 \leqq i \leqq j\right),\right.\right. \\
\left.\left.B \in \sigma\left(X_{n i}, i \geqq j+m\right)\right\}\right\}=\alpha(m) \downarrow 0 .
\end{gathered}
$$

Since $\alpha(m) \leqq \varphi(m)$, it follows that if $\left\{X_{n i}\right\}$ is $\varphi$-mixing, then it is also strong mixing.

We will study the asymptotic behavior of $\mathcal{S}_{n}(J)$ when the r.v.'s $\left\{X_{n i}\right\}$ are $\varphi$ mixing with rates

$$
\sum_{m=1}^{+\infty} m(\varphi(m))^{(2+3 \delta) /(4+2 \delta)}<+\infty \quad \text { for some } 0 \leqq \delta<2
$$

or strong mixing with rates

$$
\sum_{m=1}^{+\infty} m^{2} \alpha(m)^{\delta /(2+\delta)}<+\infty \quad \text { for some } \delta>0 .
$$

Let $F_{n, i, j}$ be the d.f. of $\left(X_{n i}, X_{n j}\right), 1 \leqq i \leqq j \leqq n, n \geqq 1$. For any sequence of d.f.'s $\left\{G_{l}^{*}, l \geqq 1\right\}$ on $[0,1]^{2}$ with uniform marginals, we denote

$$
\sigma_{J}^{2}\left(\left\{G_{l}^{*}\right\}\right)=\lim _{n \rightarrow \infty}\left\{\int_{0}^{1} f^{2}(u) d u+2 \sum_{l=1}^{n} \int_{0}^{1} \int_{0}^{1} f(u) f(v) d G_{l}^{*}(u, v)\right\}
$$

if the limit exists, where

$$
f(u)=\int_{0}^{1}\left(\mathbf{1}_{[u \leqq v]}-v\right) d J(v)+J(u)-\int_{0}^{1} J(v) d v
$$

and $J \in \mathcal{H}_{\delta}$ for some $\delta>0$.

THEOREM 3.1. Suppose the sequence $\left\{X_{n i}\right\}$ is $\varphi$-mixing with rate (3.1) or strong mixing with rate (3.2), the function $g$ which defines the regression constants in (1.1) belongs to $\mathbf{C}_{1, b}^{*}$ the space of functions which admit a derivative of bounded variation, and suppose that for any $l>1$, there exists a continuous d.f. $G_{l}^{*}$ on $[0,1]^{2}$ with uniform marginals such that

$$
\lim _{n \rightarrow \infty} \max _{1 \leqq i<j \leqq n}\left|F_{n, i, j}\left(F_{n}^{-1}(u), F_{n}^{-1}(v)\right)-G_{j-i}^{*}(u, v)\right|=0
$$


for all $(u, v)[0,1]^{2}$.

Then, for every $J \in \mathcal{G}_{\delta}$ with $2>\delta \geqq 0$ if we have (3.1), and $\delta>0$ if we have (3.2)

$$
\lim _{n \rightarrow \infty} D_{2}\left(\mathcal{L}\left(\mathcal{S}_{n}(J)\right), \mathcal{N}\left(0, \widetilde{\sigma}_{J}^{2}\left(\left\{G_{l}^{*}\right\}\right)\right)\right)=0
$$

where

$$
\tilde{\sigma}_{J}^{2}\left(\left\{G_{l}^{*}\right\}\right)=\sigma_{J}^{2}\left(\left\{G_{l}^{*}\right\}\right)
$$

$$
\times\left(\int_{0}^{1} \int_{0}^{1}(u \wedge v) g^{\prime}(u) g^{\prime}(v) d u d v-2 \int_{0}^{1} u g^{\prime}(u) d u+g^{2}(1)\right)
$$

and $\widetilde{\sigma}_{J}^{2}\left(\left\{G_{l}^{*}\right\}\right)<\infty$.

Remark 3.1. Let the sequence of distribution functions $\left\{F_{n, i, j}\right\}$ satisfy the following conditions:

(i) There exists a sequence of d.f.'s $F_{l}^{*}$ and $\mathbf{R}^{2}$ such that

$\lim _{n \rightarrow \infty} \max _{1 \leqq i<j \leqq n}\left|F_{n, i, j}\left(x_{1}, x_{2}\right)-F_{j-i}^{*}\left(x_{1}, x_{2}\right)\right|=0 \quad$ for all $\quad\left(x_{1}, x_{2}\right) \in \mathbf{R}^{2}$,

(ii) $F_{n i}=F_{n}$ for all $1 \leqq i \leqq n, n \geqq 1$,

then the condition (3.5) is satisfied whenever the sequence $\left\{X_{n i}\right\}$ is strong mixing.

Proof. To prove Theorem 3.1, we first need a few lemmas.

For any $n(n \geqq 1)$, and $i(1 \leqq i \leqq n)$ and any $J \in \mathbf{C}_{2, b}$, let

$$
\begin{aligned}
A_{n i}(J)= & \int_{0}^{1}\left(\mathbf{1}_{\left[F_{n}\left(X_{n i}\right) \leqq t\right]}-G_{n i}(t)\right) J^{\prime}(t) d G_{n i}(t) \\
& +J\left(F_{n}\left(X_{n i}\right)\right)-\int_{0}^{1} J(t) d G_{n i}(t) .
\end{aligned}
$$

It is obvious that $\mathbf{E}\left(A_{n i}\right)=0$.

Now consider for any $J \in \mathbf{C}_{2, b}$, the process $L_{n}(J)(s)$ defined on $\mathbf{C}_{1}$ the space of continuous functions on $[0,1]$, by

$$
L_{n}(J)(s)=n^{-1 / 2}\left(\sum_{i=1}^{[n s]} A_{n i}+(n s-[n s]) A_{n,[n s]+1}\right),
$$

where $[n s]$ denotes the integer part of the real number $n s$.

LEMMA 3.1. Suppose that $\left\{X_{n i}\right\}$ satisfies the conditions of Theorem 3.1 and $J$ belongs to $\mathbf{C}_{2, b}$, then the process $L_{n}(J)(s)$ converges weakly in uniform topology to a Gaussian process $L_{0}(J)(s)$ with trajectories a.s. in $\mathbf{C}_{1}$ with mean 0 and variance $s \sigma_{J}^{2}\left(\left\{G_{l}^{*}\right\}\right)$ where $\sigma_{J}^{2}\left(\left\{G_{l}^{*}\right\}\right)$ is defined in (3.3), and $\sigma_{J}^{2}\left(\left\{G_{l}^{*}\right\}\right)<\infty$.

Proof. The process $L_{n}(J)$ defines a probability measure $\mathbf{P}_{n}$ on $\mathbf{C}_{1}$. From Theorem 8.1 of [2] we have to prove that (i) the finite-dimensional distribution of $\mathbf{P}_{n}$ converges in law to a normal distribution and (ii) $\mathbf{P}_{n}$ is tight.

First we prove (i), which is equivalent to proving that $\sum_{l=1}^{p} \lambda_{l} L_{n}(J)\left(s_{l}\right)$ converges in law to a normal distribution for any $p \in \mathbf{N}^{*}$, any $l \in[0,1]$ and any $\lambda_{l} \in \mathbf{R}(1 \leqq l \leqq$ $p)$. Without loss of generality, we can take $p=2$ and suppose that $s_{1}<s_{2}$. 
We have

$$
\begin{gathered}
\sum_{l=1}^{2} \lambda_{l} L_{n}(J)\left(s_{l}\right)=n^{-1 / 2}\left[\sum_{i=1}^{\left[n s_{1}\right]}\left(\lambda_{1}+\lambda_{2}\right) A_{n i}(J)+\sum_{i=\left[n s_{1}\right]+1}^{\left[n s_{2}\right]} \lambda_{2} A_{n i}(J)\right. \\
+\lambda_{1}\left(n s_{1}-\left[n s_{1}\right]\right) A_{n,\left[n s_{1}\right]+1}(J) \\
\left.+\lambda_{2}\left(n s_{2}-\left[n s_{2}\right]\right) A_{n,\left[n s_{2}\right]+1}(J)\right] .
\end{gathered}
$$

We define the sequence of r.v.'s $\left\{B_{n i}(J)\right\}$ by

$$
B_{n i}(J)= \begin{cases}\left(\lambda_{2}+\lambda_{2}\right) A_{n i}(J) & \text { if } i \leqq\left[n s_{1}\right] \\ \lambda_{2} A_{n i}(J) & \text { if }\left[n s_{1}\right]<i \leqq\left[n s_{2}\right] \\ 0 & \text { if } i>\left[n s_{2}\right]\end{cases}
$$

As $J$ and $J^{\prime}$ are bounded, we deduce

$$
\sum_{l=1}^{2} \lambda_{l} L_{n}(J)\left(s_{l}\right)=n^{-1 / 2} \sum_{i=1}^{n} B_{n i}(J)+O\left(n^{-1 / 2}\right) .
$$

From [11, Corollary 1] we have to verify that

$$
\begin{aligned}
& \mathbf{E} \frac{1}{n}\left(\sum_{i=1}^{n} B_{n i}(J)\right)^{2} \longrightarrow\left\{\left(\lambda_{1}+\lambda_{2}\right)^{2} s_{1}+\lambda_{2}^{2}\left(s_{2}-s_{1}\right)\right\} \sigma_{J}^{2}\left(\left\{G_{l}^{*}\right\}\right) \\
& \quad \text { as } n \rightarrow \infty
\end{aligned}
$$

We have

$$
\begin{aligned}
\mathbf{E} \frac{1}{n}\left(\sum_{i=1}^{n} B_{n i}(J)\right)^{2}=\frac{1}{n}[ & \left(\lambda_{1}+\lambda_{2}\right)^{2} \sum_{i=1}^{\left[n s_{1}\right]} \sum_{j=1}^{\left[n s_{1}\right]} \mathbf{E}\left(A_{n i}(J) A_{n j}(J)\right) \\
& +\left(\lambda_{1}+\lambda_{2}\right) \lambda_{2} \sum_{i=1}^{\left[n s_{1}\right]} \sum_{j=\left[n s_{1}\right]+1}^{\left[n s_{2}\right]} \mathbf{E}\left(A_{n i}(J) A_{n j}(J)\right) \\
& \left.+\lambda_{2}^{2} \sum_{i=\left[n s_{1}\right]+1}^{\left[n s_{2}\right]} \sum_{j=\left[n s_{1}\right]+1}^{\left[n s_{2}\right]} \mathbf{E}\left(A_{n i}(J) A_{n j}(J)\right)\right] .
\end{aligned}
$$

Suppose the sequence $\left\{X_{n i}\right\}$ is $\varphi$-mixing, then from the boundedness of $J$ and $J^{\prime}$ and from the well-known inequality on the moment of $\varphi$-mixing r.v.'s (see [5, Prop. 2.2]), we obtain

$$
\begin{aligned}
\frac{1}{n} \mid & \left(\lambda_{1}+\lambda_{2}\right) \lambda_{2} \sum_{i=1}^{\left[n s_{1}\right]} \sum_{j=\left[n s_{1}\right]+1}^{\left[n s_{2}\right]} \mathbf{E}\left(A_{n i}(J) A_{n j}(J)\right) \mid \\
\leqq & \frac{M}{n} \sum_{i=1}^{\left[n s_{1}\right]} \sum_{j=\left[n s_{1}\right]+1}^{\left[n s_{2}\right]} \varphi^{1 / p}(j-i)
\end{aligned}
$$


where $M$ is some positive constant and $p=(4+2 \delta) /(2+3 \delta)$. From (3.1), the last expression goes to zero as $n \rightarrow \infty$. by

If the sequence $\left\{X_{n i}\right\}$ is strong mixing, the left-hand side of (3.15) is majorized

$$
\frac{M^{\prime}}{n} \sum_{i=1}^{\left[n s_{1}\right]} \sum_{j=\left[n s_{1}\right]+1}^{\left[n s_{2}\right]} \alpha^{\delta /(2+\delta)}(j-i)
$$

where $M^{\prime}>0$ is some constant and from (3.2), this converges to 0 as $n \rightarrow \infty$.

It remains to prove that

$$
\begin{gathered}
\frac{1}{n} \sum_{i=1}^{\left[n s_{1}\right]} \sum_{j=1}^{\left[n s_{1}\right]} \mathbf{E}\left(A_{n i}(J) A_{n j}(J)\right) \longrightarrow s_{1} \sigma_{J}^{2}\left(\left\{G_{l}^{*}\right\}\right) \\
\text { as } n \rightarrow \infty, \\
\frac{1}{n} \sum_{i=\left[n s_{1}\right]+1}^{\left[n s_{2}\right]} \sum_{j=\left[n s_{1}\right]+1}^{\left[n s_{2}\right]} \mathbf{E}\left(A_{n i}(J) A_{n j}(J)\right) \\
\text { as } n \rightarrow \infty
\end{gathered}
$$

We first prove the convergence of (3.16) when $J$ and $J^{\prime}$ are replaced by indicator functions. Suppose

$$
J(t)=\mathbf{1}_{[a \leqq t \leqq b]} \quad \text { and } \quad J^{\prime}=\mathbf{1}_{\left[a^{\prime} \leqq t \leqq b^{\prime}\right]} .
$$

Then we can write

$$
\begin{aligned}
A_{n i}(J)= & G_{n i}\left(b^{\prime}\right)-G_{n i}\left(\left\{a^{\prime} \vee F_{n}\left(X_{n i}\right)\right\} \wedge b^{\prime}\right) \\
& -\int_{a}^{b} t d G_{n i}(t)+\mathbf{1}_{\left[a \leqq F_{n}\left(X_{n i}\right) \leqq b\right]}-\left(G_{n i}(b)-G_{n i}(a)\right)=D_{n i}\left(X_{n i}^{*}\right)
\end{aligned}
$$

where $X_{n i}^{*}=F_{n}\left(X_{n i}\right)$. Let $G_{n, i, j}$ be the d.f. of $\left(F_{n}\left(X_{n i}\right), F_{n}\left(X_{n j}\right)\right)$. Then, we have

$$
\mathbf{E}\left(A_{n i}(J) A_{n j}(J)\right)=\int_{0}^{1} \int_{0}^{1} D_{n i}(u) D_{n j}(v) d G_{n, i, j}(u, v) .
$$

From condition (3.5) we easily deduce that

$$
\begin{aligned}
\lim _{n \rightarrow \infty} \max _{1 \leqq i<j \leqq n} \mid \mathbf{E}\left(A_{n i}(J) A_{n j}(J)\right) \\
-\int_{0}^{1} \int_{0}^{1} D(u) D(v) d G_{j-i}^{*}(u, v) \mid=0
\end{aligned}
$$

where

$$
D(u)=\mathbf{1}_{[a \leqq u \leqq b]}-(b-a)+b^{\prime}-\left\{\left(a^{\prime} \vee u\right) \wedge b^{\prime}\right\}-\frac{1}{2}\left(b^{\prime}-a^{\prime}\right)^{2}
$$

We obtain the same result if $J$ and $J^{\prime}$ are replaced by step functions.

As $J$ and $J^{\prime}$ are continuous and bounded, we can uniformly approach them by step functions and we deduce that

$$
\lim _{n \rightarrow \infty} \max _{1 \leqq i<j \leqq n}\left|\mathbf{E}\left(A_{n i}(J) A_{n j}(J)\right)-\int_{0}^{1} \int_{0}^{1} f(u) f(v) d G_{j-i}^{*}(u, v)\right|=0
$$


where $f(u)$ is defined in (3.4). Then,

Now denote $\rho(0)=\int_{0}^{1} f^{2}(u) d u$ and $\rho(i)=2 \int_{0}^{1} \int_{0}^{1} f(u) f(v) d G_{i}^{*}(u, v), i \geqq 1$.

$$
\begin{aligned}
& \left|n^{-1} \sum_{i=1}^{\left[n s_{1}\right]} \sum_{j=1}^{\left[n s_{1}\right]} \mathbf{E}\left(A_{n i}(J) A_{n j}(J)\right)-\left[n s_{1}\right] n^{-1} \sum_{i=0}^{+\infty} \rho(i)\right| \\
& \leqq \\
& \mid n^{-1}\left[n s_{1}\right]\left(\left[n s_{1}\right]\right)^{-1} \sum_{i=0}^{\left[n s_{1}\right]-1} \sum_{j=1}^{\left[n s_{1}\right]-i} \mathbf{E}\left(A_{n j}(J) A_{n, j+i}(J)\right) \\
& \quad-\left[n s_{1}\right]\left(n\left[n s_{1}\right]\right)^{-1} \sum_{i=0}^{\left[n s_{1}\right]}\left(\left[n s_{1}\right]-i\right) \rho(i)\left|+\left[n s_{1}\right] n^{-1} \sum_{i=\left[n s_{1}\right]+1}^{\infty}\right| \rho(i) \mid \\
& \quad+\left[n s_{1}\right] n^{-1} \sum_{i=0}^{\left[n s_{1}\right]} \sum_{k=i}^{\infty}|\rho(k)|=\left|A_{n}\right|+B_{n}+C_{n} .
\end{aligned}
$$

From (3.18) we deduce that $\left|A_{n}\right| \rightarrow 0$ as $n \rightarrow \infty$ and from the well-known inequalities on the moment of mixing r.v.'s (see [5, Props. 2.2 and 2.8]) and (3.1) or (3.2) we deduce that $B_{n} \rightarrow 0$ and $C_{n} \rightarrow 0$ and $n \rightarrow \infty$.

It is also immediate that

$$
\left|\left[n s_{1}\right] n^{-1} \sum_{i=0}^{+\infty} \rho(i)-s_{1} \sum_{i=0}^{+\infty} \rho(i)\right| \longrightarrow 0 \quad \text { as } n \rightarrow \infty .
$$

We conclude that $n^{-1} \sum_{i=1}^{\left[n s_{1}\right]} \sum_{j=1}^{\left[n s_{1}\right]} \mathbf{E}\left(A_{n i}(J) A_{n j}(J)\right)$ converges to $s_{1}\left(\sum_{i=0}^{+\infty} \rho(i)\right)$ as $n \rightarrow \infty$ where $\sum_{i=0}^{+\infty} \rho(i)$ is equal to $\sigma_{J}^{2}\left(\left\{G_{l}^{*}\right\}\right)$. Similarly

$$
\frac{1}{n} \sum_{i=\left[n s_{1}\right]+1}^{\left[n s_{2}\right]} \sum_{j=\left[n s_{1}\right]+1}^{\left[n s_{2}\right]} \mathbf{E}\left(A_{n i}(J) A_{n j}(J)\right) \longrightarrow\left(s_{2}-s_{1}\right) \sigma_{J}^{2}\left(\left\{G_{l}^{*}\right\}\right)
$$

as $n \rightarrow \infty$, so (3.16) is proved.

From (3.14)-(3.16), we deduce (3.13) and we conclude that $\mathbf{E}\left(\sum_{l=1}^{2} \lambda_{l} L_{n}(J)\left(s_{l}\right)\right)^{2}$ converges to $\left\{\left(\lambda_{1}+\lambda_{2}\right)^{2} s_{1}+\lambda_{2}^{2}\left(s_{2}-s_{1}\right)\right\} \sigma_{J}^{2}\left(\left\{G_{l}^{*}\right\}\right)$ which implies that $\sum_{l=1}^{2} \lambda_{l} L_{n}(J)\left(s_{l}\right)$ converges in law to the normal distribution with mean 0 and variance $\left\{\left(\lambda_{1}+\lambda_{2}\right)^{2} s_{1}+\right.$ $\left.\lambda_{2}^{2}\left(s_{2}-s_{1}\right)\right\} \sigma_{J}^{2}\left(\left\{G_{l}^{*}\right\}\right)$ and (i) is proved.

We now prove (ii).

From [2, Thm. 8.2] we have to verify that $\forall \varepsilon>0 \exists \eta>0(0<\eta<1)$ and an integer $N_{0}$ such that $\forall n \geqq N_{0}$

$$
\mathbf{P}\left[\sup _{\left|s-s^{\prime}\right|<\eta}\left|L_{n}(J)(s)-L_{n}(J)\left(s^{\prime}\right)\right| \geqq \varepsilon\right] \leqq \varepsilon .
$$

If $n s$ and $n s^{\prime}$ are integers, by using Theorem 11 from [5] for $q=4$ for the strong mixing case and Lemma 5.1 in Harel (1988) for $q=2$ for the $\varphi$-mixing case, we obtain for $s \geqq s^{\prime}$

$$
\mathbf{E}\left(L_{n}(J)(s)-L_{n}(J)\left(s^{\prime}\right)\right)^{4} \leqq\left(\left(s-s^{\prime}\right)^{2}+n^{-1}\left(s-s^{\prime}\right)\right) M C(\beta)
$$


where

$$
C(\beta)=\sum_{m=1}^{+\infty} m^{-1} \varphi^{1 / 4}(m)
$$

if the sequence $\left\{X_{n i}\right\}$ is $\varphi$-mixing, and

$$
C(\beta)=\sum_{m=1}^{+\infty} m^{2} \alpha^{\delta /(2+\delta)}(m)
$$

if the sequence $\left\{X_{n i}\right\}$ is strong mixing and $M$ is some positive constant.

If $s>s^{\prime}$ and $n s$ and $n s^{\prime}$ are integers, we have $s-s^{\prime} \geqq n^{-1}$ and

$$
\mathbf{E}\left(L_{n}(J)(s)-L_{n}(J)\left(s^{\prime}\right)\right)^{4} \leqq 2 M\left(s-s^{\prime}\right)^{2} C(\beta) .
$$

From [1, Lemma 2] we obtain that for any $\varepsilon>0$ there exist $\eta>0$, and an integer $N_{0}$ sufficiently large such that $\forall n \geqq N_{0}$,

$$
\begin{aligned}
& \mathbf{P}\left[\sup _{\left|[n s] / n-\left[n s^{\prime}\right] / n\right|<2 \eta}\left|L_{n}(J)([n s] / n)-L_{n}(J)\left(\left[n s^{\prime}\right] / n\right)\right|>\varepsilon / 2\right] \\
& \quad \leqq 2 M C(\beta) K \eta^{2} \varepsilon^{-4}
\end{aligned}
$$

where $K$ is some positive constant.

From the definition of $L_{n}(J)(s)$ in (3.9), we obtain

$$
\begin{aligned}
& \sup _{\left|s-s^{\prime}\right|<\eta}\left|L_{n}(J)(s)-L_{n}(J)\left(s^{\prime}\right)\right| \\
& \quad \leqq 2 \max _{\left|[n s] / n-\left[n s^{\prime}\right] / n\right|<2 \eta}\left|L_{n}(J)([n s] / n)-L_{n}(J)\left(\left[n s^{\prime}\right] / n\right)\right| .
\end{aligned}
$$

By using (3.23) and (3.24), we deduce

$$
\mathbf{P}\left[\sup _{\left|s-s^{\prime}\right|<\eta}\left|L_{n}(J)(s)-L_{n}(J)\left(s^{\prime}\right)\right| \geqq \varepsilon\right] \leqq M C(\beta) K^{\prime} \eta^{2} \varepsilon^{-4}
$$

where $K^{\prime}$ is some positive constant and (3.19) is proved. The fact that $\sigma_{J}^{2}\left(\left\{G_{l}^{*}\right\}\right)<\infty$ is a simple consequence of $J \in \mathbf{C}_{2, b}$ and (3.1) or (3.2).

Now we consider for any $J \in \mathbf{C}_{2, b}$ the r.v. $V_{n}(J)$ defined by

$$
V_{n}(J)=n^{-1 / 2} \sum_{i=1}^{n} c_{n i} A_{n i} .
$$

LEMma 3.2 Suppose that $\left\{X_{n i}\right\}$ satisfies the conditions of Theorem $3.1, J$ belongs to $\mathbf{C}_{2, b}$ and $g$ admits a derivative $g^{\prime}$. Then $V_{n}(J)$ converges in law to the normal distribution with mean 0 and variance $\widetilde{\sigma}_{J}^{2}\left(\left\{G_{l}^{*}\right\}\right)$ where $\widetilde{\sigma}_{J}^{2}\left(\left\{G_{l}^{*}\right\}\right)$ is defined in (3.7) and $\widetilde{\sigma}_{J}^{2}\left(\left\{G_{l}^{*}\right\}\right)<\infty$.

Proof. For any $n$ define a measure $\lambda_{n}$ on $[0,1]$ by setting

$$
\lambda_{n}(\{i / n\})=c_{n i}-c_{n, i+1}, \quad 1 \leqq i \leqq n-1, \quad \text { and } \quad \lambda_{n}(\{1\})=c_{n n} .
$$

By definition, we have

$$
V_{n}(J)=\int_{0}^{1} L_{n}(J)(u) \lambda_{n}(d u)
$$


We now prove that

$$
\begin{gathered}
\int_{0}^{1} L_{n}(J)(u) \lambda_{n}(d u) \quad \text { converges in law to } \\
-\int_{0}^{1} L_{0}(J)(u) g^{\prime}(u) d u+L_{0}(J)(1) g(1) \quad \text { as } n \rightarrow \infty .
\end{gathered}
$$

Let $h_{n}: \mathbf{C}_{1} \rightarrow \mathbf{R}, n \geqq 1$, be defined as $h_{n}(f)=\int_{0}^{1} f(u) \lambda_{n}(d u)$ and $h_{0}: \mathbf{C}_{1} \rightarrow \mathbf{R}$ be defined as $h_{0}(f)=-\int_{0}^{1} f g^{\prime}(u) d u+f(1) g(1)$. Let $\left\{f_{n}, n \geqq 1\right\}$ be a sequence of functions in $\mathbf{C}_{1}$ and suppose that $f_{n} \rightarrow f_{0}$ in uniform topology as $n \rightarrow \infty$ where $f_{0} \in \mathbf{C}_{1}$. We show that $h_{n}\left(f_{n}\right) \rightarrow h_{0}\left(f_{0}\right)$ as $n \rightarrow \infty$.

$$
\begin{aligned}
& \left|\int_{0}^{1} f_{n}(u) \lambda_{n}(d u)-\left(-\int_{0}^{1} f_{0}(u) g^{\prime}(u)+f_{0}(1) g(1)\right)\right| \\
& \leqq \\
& \quad\left|\int_{0}^{1}\left(f_{n}(u)-f_{0}(u)\right) \lambda_{n}(d u)\right| \\
& \quad+\left|\int_{0}^{1} f_{0}(u) \lambda_{n}(d u)+\int_{0}^{1} f_{0}(u) g^{\prime}(u)-f_{0}(1) g(1)\right| \\
& \leqq \sup _{u \in[0,1]}\left|f_{n}(u)-f_{0}(u)\right|\left|\int_{0}^{1} \lambda_{n}(d u)\right| \\
& \quad+\mid \sum_{i=1}^{n-1} f_{0}(i / n)(g(i / n)-g((i+1) / n))+f_{0}(1) g(1) \\
& \quad+\int_{0}^{1} f_{0}(u) g^{\prime}(u) d u-f_{0}(1) g(1) \mid \longrightarrow 0 \quad \text { as } n \rightarrow \infty
\end{aligned}
$$

from the hypothesis $f_{n} \rightarrow f_{0}$ in uniform topology, $g^{\prime}$ is an integrable function and $\sup _{n \in \mathbf{N}^{*}} \Lambda_{n}<\infty$.

Consequently, $h_{n}\left(f_{n}\right) \rightarrow h_{0}\left(f_{0}\right)$ as $n \rightarrow \infty$ and by [2, Thm. 5.5] (3.27) follows.

It remains to show that

$$
\mathbf{E}\left(-\int_{0}^{1} L_{0}(J)(u) g^{\prime}(u) d u+L_{0}(J)(1) g(1)\right)^{2}=\widetilde{\sigma}_{J}\left(\left\{G_{l}^{*}\right\}\right)<\infty .
$$

We have

$$
\begin{aligned}
\mathbf{E}( & \left.-\int_{0}^{1} L_{0}(J)(u) g^{\prime}(u) d u+L_{0}(J)(1) g(1)\right)^{2} \\
= & \int_{0}^{1} \int_{0}^{1} \mathbf{E}\left[L_{0}(J)(u) L_{0}(J)(v)\right] g^{\prime}(u) g^{\prime}(v) d u d v \\
& -2 \int_{0}^{1} \mathbf{E}\left[L_{0}(J)(1) L_{0}(J)(u)\right] g^{\prime}(u) d u+\mathbf{E}\left[L_{0}(J)(1) L_{0}(J)(1)\right] g^{2}(1) .
\end{aligned}
$$

As $\mathbf{E}\left[L_{0}(J)(u) L_{0}(J)(v)\right]=(u \wedge v) \sigma_{J}^{2}\left(\left\{G_{l}^{*}\right\}\right)<\infty$, the property follows and Lemma 3.2 is proved.

Proof of the theorem. We first prove that the theorem is true for $J \in \mathbf{C}_{2, b}$. We have the following decomposition:

$$
\mathcal{S}_{n}(J)=V_{n}(J)+A_{n}(J)+B_{n}(J)+C_{n}(J),
$$


where

$$
\begin{aligned}
& A_{n}(J)=n^{1 / 2} \int_{0}^{1} J^{\prime}\left(I_{n}(t)\right)\left(\hat{I}_{n}(t)-I_{n}(t)\right) d\left(\widehat{G}_{n}-G_{n}\right)(t) \\
& B_{n}(J)=-(n+1)^{-1} n^{1 / 2} \int_{0}^{1} J^{\prime}\left(I_{n}(t)\right) \hat{I}_{n}(t) d \widehat{G}_{n}(t) \\
& C_{n}(J)=2^{-1} n^{1 / 2} \int_{0}^{1} J^{\prime \prime}\left(\theta_{n}\left(I_{n}(t)\right)\right)\left(n(n+1)^{-1}\left(\hat{I}_{n}(t)-I_{n}(t)\right)\right)^{2} d \widehat{G}_{n}(t),
\end{aligned}
$$

where $\theta_{n}\left(I_{n}(t)\right) \in\left[I_{n}(t) \wedge \hat{I}_{n}(t), I_{n}(t) \vee \hat{I}_{n}(t)\right]$.

Suppose $J \in \mathbf{C}_{2, b}$. Then the weak convergence of $V_{n}(J)$ is established in Lemma 3.2. The random variables $A(J), B(J), C(J)$ converge to zero in probability and in $\mathbf{L}_{2}$, since

$$
\begin{gathered}
\mathbf{E}\left(A_{n}^{2}(J)\right) \leqq K n^{-1} \sup _{t \in[0,1]}\left|J^{\prime}(t)\right|^{2} \sup _{n \in \mathbf{N}^{*}} \Lambda_{n}^{2} C(\beta), \\
\left|B_{n}(J)\right| \leqq K n^{-1 / 2} \sup _{t \in[0,1]}\left|J^{\prime}(t)\right| \sup _{n \in \mathbf{N}^{*}} \Lambda_{n}, \\
\mathbf{E}\left(C_{n}^{2}(J)\right) \leqq K n^{-1} \sup _{t \in[0,1]}\left|J^{\prime}(t)\right|^{2} \sup _{n \in \mathbf{N}^{*}} \Lambda_{n}^{2} C(\beta)
\end{gathered}
$$

where $C(\beta)=\sum_{m=1}^{+\infty} m(\varphi(m))^{(2+3 \delta) /(4+2 \delta)}$ if we have $(3.1)$, and $C(\beta)=m^{2} \times$ $\sum_{m=1}^{+\infty}(\alpha(m))^{\delta /(2+\delta)}$ if we have (3.2), and $K$ is some positive constant.

We only prove the inequality (3.28) for the $\varphi$-mixing case, because the method is similar to the proof of the three inequalities in $\left[4\right.$, p. 66]. For any $(i, j, l, q) \in \mathbf{N}^{4}$, we put

$$
\begin{aligned}
\beta(i, j, l, q)= & \left(\int_{0}^{1} J^{\prime}\left(I_{n}(t)\right) c_{n i}\left(\mathbf{1}_{\left[X_{n i} \leqq t\right]}-F_{n i}(t)\right) d\left(\mathbf{1}_{\left[X_{n j} \leqq t\right]}-F_{n j}(t)\right)\right) \\
& \times\left(\int_{0}^{1} J^{\prime}\left(I_{n}(u)\right) c_{n l}\left(\mathbf{1}_{\left[X_{n l} \leqq u\right]}-F_{n l}(u)\right) d\left(\mathbf{1}_{\left[X_{n q} \leqq u\right]}-F_{n q}(u)\right)\right) .
\end{aligned}
$$

Suppose $i \leqq j \leqq l \leqq q$ and let $p=(2+3 \delta) /(4+2 \delta)$, then from the condition of $\varphi$-mixing, we have the following three inequalities:

$$
\begin{aligned}
& \beta(i, j, l, q) \leqq \sup _{t \in[0,1]}\left|J^{\prime}(t)\right|^{2} \Lambda_{n}^{2} \varphi(j-i), \\
& \beta(i, j, l, q) \leqq\left(2 \sup _{t \in[0,1]}\left|J^{\prime}(t)\right|^{2} \Lambda_{n}^{2}\right)\left(\varphi(l-j)+4 \varphi^{1 / p}(j-i) \varphi^{1 / p}(q-l)\right), \\
& \beta(i, j, l, q) \leqq \sup _{t \in[0,1]}\left|J^{\prime}(t)\right|^{2} \Lambda_{n}^{2} \varphi(q-l) .
\end{aligned}
$$

If $i, j, l, q$ are differently ordered, we obtain similar inequalities.

From this, we deduce

$$
\mathbf{E}\left(A_{n}^{2}(J)\right) \leqq 4 ! n^{-3} \sup _{t \in[0,1]}\left|J^{\prime}(t)\right|^{2} \Lambda_{n}^{2} \sum_{i, j, l, q} \beta(i, j, l, q) .
$$


Put $j^{\prime}=j-i, l^{\prime}=l-j$ and $q^{\prime}=q-l$. We have

$$
\begin{aligned}
& \mathbf{E}\left(A_{n}^{2}(J)\right) \leqq 4 ! n^{-3} \sup _{t \in[0,1]}\left|J^{\prime}(t)\right|^{2} \Lambda_{n}^{2} \\
& \quad \times \sum_{i=1}^{n}\left(\sum_{\substack{0 \leqq \prime^{\prime} \leqq j^{\prime} \\
0 \leqq q^{\prime} \leqq j^{\prime}}} 2 \varphi\left(j^{\prime}\right)+\sum_{\substack{0 \leqq j^{\prime} \leqq q^{\prime} \\
0 \leqq l^{\prime} \leqq q^{\prime}}} 2 \varphi\left(q^{\prime}\right)+\sum_{\substack{0 \leqq j^{\prime} \leqq l^{\prime} \\
0 \leqq q^{\prime} \leqq l^{\prime}}} 2 \varphi\left(l^{\prime}\right)+4 \varphi^{1 / p}\left(j^{\prime}\right) \varphi^{1 / p}\left(q^{\prime}\right)\right)
\end{aligned}
$$

and after some computations, we obtain

$$
\begin{aligned}
\mathbf{E}\left(A_{n}^{2}(J)\right) & \leqq 288 n^{-3} \sup _{t \in[0,1]}\left|J^{\prime}(t)\right|^{2} \Lambda_{n}^{2}\left(\sum_{m \geqq 1} \varphi^{1 / p}(m)\right)\left(\sum_{m \geqq 1} m \varphi^{1 / p}(m) / m\right)\left(n+n^{2}\right) \\
& \leqq K n^{-1} \sup _{t \in[0,1]}\left|J^{\prime}(t)\right|^{2} \sup _{n \in \mathbf{N}^{*}} \Lambda_{n}^{2} C(\beta)
\end{aligned}
$$

where $K$ is some positive constant and $C(\beta)=\sum_{m \geqq 1} m(\varphi(m))^{(2+3 \delta) /(4+2 \delta)}$. The inequality (3.28) is proved for the $\varphi$-mixing case. Hence the theorem is true for $J \in \mathbf{C}_{2, b}$.

Following Proposition 2.3 it remains to prove that the operator $\sigma: \mathcal{H}_{\delta} \rightarrow \mathbf{R}$ defined by $\sigma(J)=\widetilde{\sigma}_{J}\left(\left\{G_{l}^{*}\right\}\right)$ satisfies the Lipschitz condition for the \|\|$_{\delta}$ norm and the condition (2.5) is satisfied. The first property follows easily from the definition of $\widetilde{\sigma}_{J}\left(\left\{G_{l}^{*}\right\}\right)$ in (3.7) and the definition of $\sigma_{J}\left(\left\{G_{l}^{*}\right\}\right)$ in (3.3) and (3.4).

We now prove (2.5) if we have (3.1). For $p=(4+2 \delta) /(2+3 \delta)$ and $q=\left(1-p^{-1}\right)^{-1}$ we have

$$
\begin{aligned}
n \mathbf{E} & \left(\widehat{G}_{n}(t)-G_{n}(t)\right)^{2}=n \mathbf{E}\left[n^{-1} \sum_{i=1}^{n} c_{n i}\left(\mathbf{1}_{\left[F_{n}\left(X_{n i}\right) \leqq t\right]}-G_{n i}(t)\right)\right]^{2} \\
= & n^{-1} \sum_{1 \leqq i, j \leqq n} \mathbf{E}\left[c_{n i} c_{n j}\left(\mathbf{1}_{\left[F_{n}\left(X_{n i}\right) \leqq t\right]}-G_{n i}(t)\right)\left(\mathbf{1}_{\left[F_{n}\left(X_{n j}\right) \leqq t\right]}-G_{n j}(t)\right)\right] \\
\leqq & 2 n^{-1} \Lambda_{n}^{2} \sum_{i=0}^{n-1} \sum_{j=1}^{n-i} \mathbf{E}\left|\left(\mathbf{1}_{\left[F_{n}\left(X_{n i}\right) \leqq t\right]}-G_{n i}(t)\right)\left(\mathbf{1}_{\left[F_{n}\left(X_{n, j+i}\right) \leqq t\right]}-G_{n, j+1}(t)\right)\right| \\
\leqq & 2 n^{-1} \Lambda_{n}^{2} \sum_{i=0}^{n-1} \varphi^{1 / p}(i) \sum_{j=1}^{n-i}\left(G_{n, j}(t)\left(1-G_{n, j}(t)\right)\right)^{1 / p} \\
& \times\left(G_{n, j+i}(t)\left(1-G_{n, j+i}(t)\right)\right)^{1 / q} \\
\leqq & 2 n^{-1} \Lambda_{n}^{2} \sum_{i=1}^{n-1} \varphi^{1 / p}(i)\left(\sum_{j=1}^{n} G_{n, j}(t)\left(1-G_{n, j}(t)\right)\right)^{1 / p} \\
& \times\left(\sum_{j=1}^{n} G_{n, j}(t)\left(1-G_{n, j}(t)\right)\right)^{1 / q} \\
\leqq & 2 n^{-1} \Lambda_{n}^{2} \sum_{i=1}^{n-1} \varphi^{1 / p}(i)\left(\sum_{j=1}^{n} G_{n, j}(t)\left(1-G_{n, j}(t)\right)\right)^{n} \\
\leqq & \left.2 n^{-1} \Lambda_{n}^{2} \sum_{i=1}^{n-1} \varphi^{1 / p}(i) n\left(\frac{1}{n} \sum_{j=1}^{n} G_{n j}(t)\right)\left(1-n^{-1} \sum_{j=1}^{n} G_{n j}(t)\right)^{1}\right)
\end{aligned}
$$




$$
=2 \Lambda_{n}^{2} \sum_{i=1}^{n-1} \varphi^{1 / p}(i) t(1-t) \leqq 2\left(\sum_{i=1}^{+\infty} \varphi^{1 / p}(i)\right) \Lambda_{n}^{2} t(1-t),
$$

which implies (2.5) if we have (3.1).

Finally, we prove (2.5) if we have (3.2). We have in analogy with preceding arguments

$$
\begin{aligned}
n \mathbf{E}(\widehat{G}(t) & \left.-G_{n}(t)\right)^{2} \leqq 2 n^{-1} \Lambda_{n}^{2} \sum_{i=0}^{n-1}(\alpha(i))^{\delta /(2+\delta)} \sum_{j=1}^{n-i}\left(G_{n j}(t)(1\right. \\
& \left.\left.-G_{n j}(t)\right)\right)^{1 /(2+\delta)}\left(G_{n, j+i}(t)\left(1-G_{n, j+i}(t)\right)\right)^{1 /(2+\delta)} \\
\leqq & 2 n^{-1} \Lambda_{n}^{2} \sum_{i=0}^{n-1}(\alpha(i))^{\delta /(2+\delta)}\left(\sum_{j=1}^{n} G_{n j}\left(1-G_{n j}(t)\right)\right)^{1 /(2+\delta)} \\
& \times\left(\sum_{j=1}^{n} G_{n, j}(t)\left(1-G_{n, j}(t)\right)\right)^{1 /(2+\delta)} \\
= & 2 n^{-1} \Lambda_{n}^{2} \sum_{i=0}^{n-1}(\alpha(i))^{2 /(2+\delta)}\left(\sum_{j=1}^{n} G_{n j}(t)\left(1-G_{n j}(t)\right)\right)^{2 /(2+\delta)} \\
\leqq & 2 n^{-1} \Lambda_{n}^{2} \sum_{i=0}^{n-1}(\alpha(i))^{\delta /(2+\delta)} n\left(n^{-1} \sum_{j=1}^{n} G_{n j}(t)\left(1-n^{-1} \sum_{j=1}^{n} G_{n j}(t)\right)\right)^{2 /(2+\delta)} \\
= & 2 \Lambda_{n}^{2} \sum_{i=0}^{n-1}(\alpha(i))^{\delta /(2+\delta)}(t(1-t))^{2 /(2+\delta)} \\
\leqq & 2 \Lambda_{n}^{2} \sum_{i=0}^{+\infty}(\alpha(i))^{2 /(2+\delta)}(t(1-t))^{1-2 \eta} \text { for } \eta=\delta(4+2 \delta)^{-1} .
\end{aligned}
$$

Thus (2.5) is proved if we have (3.2).

COROLlARY 3.1. If among conditions in Theorem 3.1 the function $g$ is replaced by a function for which there exists a decomposition $g=g_{c}+g_{d}$ where $g_{c} \in \mathbf{C}_{1, b}^{*}$ and $g_{d}$ is a step function with $p$ jumps, say at $a_{1}, \ldots, a_{p}$ such that $a_{i} \in(0,1)(1 \leqq i \leqq p)$, then the conclusion of Theorem 3.1 remains true but $\widetilde{\sigma}_{J}\left(\left\{G_{l}^{*}\right\}\right)$ defined in (3.7) is replaced by $\widehat{\sigma}_{J}^{2}\left(\left\{G_{l}^{*}\right\}\right)$ where

$$
\begin{aligned}
\widehat{\sigma}_{J}^{2}\left(\left\{G_{l}^{*}\right\}\right)= & \sigma_{J}^{2}\left(\left\{G_{l}^{*}\right\}\right)\left(\int_{0}^{1} \int_{0}^{1}(u \wedge v) g_{c}^{\prime}(u) g_{c}^{\prime}(v) d u d v\right. \\
& -2 \sum_{i=1}^{p}\left(g_{d}\left(a_{i}-\right)-g_{d}\left(a_{i}+\right)\right) \int_{0}^{1}\left(u \wedge a_{i}\right) g_{c}^{\prime}(u) d u \\
& -2 \int_{0}^{1} u g_{c}^{\prime}(u) d u+\sum_{1<i, j \leqq p}\left(a_{i} \wedge a_{j}\right)\left(g_{d}\left(a_{i}-\right)\right. \\
& \left.\left.-g_{d}\left(a_{i}+\right)\right)\left(g_{d}\left(a_{j}-\right)-g_{d}\left(a_{j}+\right)\right)+2 \sum_{i=1}^{p} a_{i}\left(g_{d}\left(a_{i}-\right)-g_{d}\left(a_{i}+\right)\right)+g^{2}(1)\right)
\end{aligned}
$$

where $\sigma_{J}^{2}\left(\left\{G_{l}^{*}\right\}\right)$ is defined in (3.3). 
4. Convergence of the two-sample linear rank statistic. Let $\left\{Y_{n_{1} i}\right\}, 1 \leqq$ $i \leqq n_{1}$, and $\left\{Z_{n_{2} j}\right\}, 1 \leqq j \leqq n_{2}$, be two independent sequences of weakly dependent random variables with continuous d.f.'s $F_{n_{1} i}^{(1)}(x)$ and $F_{n_{2} j}^{(2)}(x)$, respectively, $x \in \mathbf{R}$. Given $n=n_{1}+n_{2}$ we set $X_{n i}=Y_{n_{1} i}$ if $i \leqq n_{1}$ and $X_{n i}=Y_{n_{2} i-n_{1}}$ if $i>n_{1}$. Denote by $\widehat{F}_{n_{1}}^{(1)}(x)=n_{1}^{-1} \sum_{i=1}^{n_{1}} c_{n_{1} i} \mathbf{1}_{\left[X_{n i} \leqq x\right]}$ the empirical process based on the first sequence of r.v.'s $\left\{Y_{n_{1} i}\right\}$ and weighted by the regression constants $c_{n_{1} i}$. We put $F_{n_{1}}^{(1)}=\mathbf{E}\left(\widehat{F}_{n_{1}}^{(1)}\right)$.

Then $\mathcal{S}_{n}^{*}(J)$ defined by

$$
\mathcal{S}_{n}^{*}(J)=n^{1 / 2}\left(\int_{-\infty}^{+\infty} J\left(\frac{n}{n+1} \widehat{F}_{n}(x)\right) d \widehat{F}_{n_{1}}^{(1)}(x)-\int_{-\infty}^{+\infty} J\left(F_{n}(x)\right) d F_{n_{1}}^{(1)}(x)\right)
$$

is the two-sample linear rank statistic. We suppose that the regression constants $c_{n_{1} i}$ $\left(1 \leqq i \leqq n_{1}\right)$ are defined by a function $h$ on $[0,1]$ as

$$
c_{n_{1} i}=h\left(i / n_{1}\right), \quad 1 \leqq i \leqq n_{1}, \quad n_{1} \geqq 1 .
$$

We assume that $n_{1} n^{-1} \rightarrow \lambda_{0} \in(0,1)$.

We have $F_{n}=n^{-1}\left(\sum_{i=1}^{n_{1}} F_{n_{1} i}^{(1)}+\sum_{j=1}^{n_{2}} F_{n_{2} j}^{(2)}\right)$.

Let $F_{n_{1}, i, l}^{(1)}$ be the d.f. of $\left(Y_{n_{1} i}, Y_{n_{1} l}\right)$ and $F_{n_{2}, j, k}^{(2)}$ be the d.f. of $\left(Z_{n_{2} j}, Z_{n_{2} k}\right)$.

THEOREM 4.1. Suppose the sequences $\left\{Y_{n_{1} i}\right\}$ and $\left\{Z_{n_{2} j}\right\}$ are $\varphi$-mixing with rate (3.1) or strong mixing with rate (3.2), the function $h$ satisfies $h=h_{c}+h_{d}$ with $h_{c} \in \mathbf{C}_{1, b}^{*}$ and $h_{d}$ is a step function and if for each $p>1$, there exist two continuous d.f.' $s \widehat{G}_{p}^{(1)}$ and $\widehat{G}_{p}^{(2)}$ on $\mathbf{R}^{2}$ with marginals $F^{(1)}$ and $F^{(2)}$ such that

$$
\lim _{n \rightarrow \infty} \max _{1 \leqq i<j \leqq n}\left|F_{n_{l}, i, j}^{(l)}\left(F_{n}^{-1}\left(t_{1}\right), F_{n}^{-1}\left(t_{2}\right)\right)-\widehat{G}_{j-i}^{(l)}\left(H^{-1}\left(t_{1}\right), H^{-1}\left(t_{2}\right)\right)\right|=0
$$

for all $\left(t_{1}, t_{2}\right) \in[0,1]^{2}, l=1,2$, where

$$
H=\lambda_{0} F^{(1)}+\left(1-\lambda_{0}\right) F^{(2)} \text {. }
$$

Then, for every $J \in \mathcal{G}_{\delta}$ with $2>\delta \geqq 0$ if we have (3.1) and $\delta>0$ if we have (3.2)

$$
\lim D_{2}\left(\mathcal{L}\left(\mathcal{S}_{n}^{*}(J)\right), \mathcal{N}\left(0, \widetilde{\sigma}_{J}\left(\left\{G_{p}^{(l)}\right\}\right)\right)\right)=0
$$

where

$$
\widetilde{\sigma}_{J}^{2}\left(\left\{\widehat{G}_{p}^{(l)}\right\}\right)=\bar{\sigma}_{J}^{2}\left(\left\{\widehat{G}_{p}^{(l)}\right\}\right) L(h)
$$

where

$$
\begin{aligned}
& \begin{aligned}
\bar{\sigma}_{J}^{2}\left(\left\{G_{p}^{(l)}\right\}\right)=\lambda_{0}^{-1}\left\{\int_{0}^{1} f_{1}^{2}(u) d\left(F^{(1)} \circ H^{-1}\right)(u)\right. \\
\left.+2 \sum_{p \geqq 2} \int_{0}^{1} \int_{0}^{1} f_{1}(u) f_{1}(v) d\left(\widehat{G}_{p}^{(1)}\left(H^{-1}(u), H^{-1}(v)\right)\right)\right\} \\
+\left(1-\lambda_{0}\right)\left\{\int_{0}^{1} f_{2}^{2}(u) d\left(F^{(2)} \circ H^{-1}\right)(u)\right. \\
\left.+2 \sum_{p \geqq 2} \int_{0}^{1} \int_{0}^{1} f_{2}(u) f_{2}(v) d\left(\widehat{G}_{p}^{(2)}\left(H^{-1}(u), H^{-1}(v)\right)\right)\right\} .
\end{aligned} \\
& \begin{array}{l}
\text { (4.6) }
\end{array}
\end{aligned}
$$


Here

$$
\begin{aligned}
& f_{1}(u)=f_{1}^{*}(u)-\int_{0}^{1} f_{1}^{*}(v) d\left(F^{(1)} \circ H^{-1}(v)\right), \\
& f_{2}(u)=f_{2}^{*}(u)-\int_{0}^{1} f_{2}^{*}(v) d\left(F^{(2)} \circ H^{-1}(v)\right),
\end{aligned}
$$

with

$$
\begin{aligned}
& f_{1}^{*}(u)=J(u)+\lambda_{0} \int_{u}^{1} J^{\prime}(v) d\left(F^{(1)} \circ H^{-1}(v)\right) \\
& f_{2}^{*}(u)=\int_{u}^{1} J^{\prime}(v) d\left(F^{(2)} \circ H^{-1}(v)\right)
\end{aligned}
$$

and

$$
\begin{aligned}
L(h)= & \int_{0}^{1} \int_{0}^{1} h_{c}^{\prime}(u) h_{c}^{\prime}(v) d u d v-2 \sum_{i=1}^{p}\left(h_{d}\left(a_{i}-\right)-h_{d}\left(a_{i}+\right)\right) \int_{0}^{1} h_{c}(u) d u \\
& -2 \int_{0}^{1} h_{c}^{\prime}(u) d u+\sum_{1 \leqq i, j \leqq p}\left(h_{d}\left(a_{i}-\right)-h_{d}\left(a_{i}+\right)\right)\left(h_{d}\left(a_{j}-\right)-h_{d}\left(a_{j}+\right)\right) \\
& +2 \sum_{i=1}^{p}\left(h_{d}\left(a_{i}-\right)-h_{d}\left(a_{i}+\right)\right)+h_{c}^{2}(1),
\end{aligned}
$$

where $a_{i}, 1 \leqq i \leqq p$, are the discontinuous points of $h_{d}$.

Remark. Let the sequences $\left\{F_{n_{1}, i, j}^{(1)}\right\}$ and $\left\{F_{n_{2}, i, j}^{(2)}\right\}$ satisfy the following conditions:

(i) there exist two sequences of d.f.'s $G_{p}^{(l)}$ on $\mathbf{R}^{2}, l=1$, 2 , such that

$$
\lim _{n \rightarrow \infty} \max _{1 \leqq i<j \leqq n}\left|F_{n_{l}, i, j}^{(l)}\left(x_{1}, x_{2}\right)-G_{j-1}^{(l)}\left(x_{1}, x_{2}\right)\right|=0
$$

for all $\left(x_{1}, x_{2}\right) \in \mathbf{R}^{2}, l=1,2$,

(ii) $F_{n_{1} i}^{(1)}=F_{n_{1}}^{(1)}$ for all $1 \leqq i \leqq n_{1}$,

(iii) $F_{n_{2} j}^{(2)}=F_{n_{2}}^{(2)}$ for all $1 \leqq j \leqq n_{2}$.

Then condition (4.2) is satisfied when the sequences $\left\{Y_{n_{1} i}\right\}$ and $\left\{Z_{n_{2} j}\right\}$ are strong mixing. let

Proof of Theorem 4.2. For any $n_{1} \geqq 1$, for any $i\left(1 \leqq i \leqq n_{1}\right)$ and for any $J \in \mathbf{C}_{2, b}$,

$$
\begin{aligned}
B_{n_{1} i}(J)= & n_{1} n^{-1} \int_{0}^{1}\left(\mathbf{1}_{\left[F_{n}\left(Y_{n_{1} i}\right) \leqq t\right]}-G_{n_{1} i}^{(1)}(t)\right) J^{\prime}(t) d G_{n_{1} i}^{(1)}(t) \\
& +J\left(F_{n}\left(Y_{n_{1} i}\right)\right)-\int_{0}^{1} J(t) d G_{n_{1} i}^{(1)}(t)
\end{aligned}
$$

where $G_{n_{1} i}^{(1)}=F_{n_{1} i}^{(1)} \circ F_{n}^{-1}$, and for any $n_{2} \geqq 1$, any $j\left(1 \leqq j \leqq n_{2}\right)$, any $J \in \mathbf{C}_{2, b}$ and any $u \in[0,1]$, let

$$
\begin{aligned}
C_{n_{2} j}(J)(u)= & n_{2}^{-1} \sum_{l=1}^{\left[n_{2} u\right]} \int_{0}^{1}\left(\mathbf{1}_{\left[F_{n}\left(Z_{n_{2} j}\right) \leqq t\right]}-G_{n_{2} j}^{(2)}(t)\right) J^{\prime}(t) d G_{n_{2} l}^{(2)}(t) \\
& +n_{2}^{-1}\left(n_{2} u-\left[n_{2} u\right]\right) \int_{0}^{1}\left(\mathbf{1}_{\left[F_{n}\left(Z_{n_{2} j}\right) \leqq t\right]}-G_{n_{2} j}^{(2)}(t)\right) d G_{n_{2},\left[n_{2} u\right]+1}^{(2)}(t),
\end{aligned}
$$


where $G_{n_{2} j}^{(2)}=F_{n_{2} j}^{(2)} \circ F_{n}^{-1}$.

Now consider for any $J \in \mathbf{C}_{2, b}$ the processes $W_{n_{1}}(J)(s)$ and $W_{n_{2}}^{*}(J)(s, u)$ defined, respectively, on $\mathbf{C}_{1}$ and $\mathbf{C}_{1}^{*}$ (= the space of continuous functions on $[0,1]^{2}$ ) by

$$
\begin{aligned}
W_{n_{1}}(J)(s) & =n_{1}^{1 / 2}\left(\sum_{i=1}^{\left[n_{1} s\right]} B_{n_{1} i}(J)+\left(n_{1} s-\left[n_{1} s\right]\right) B_{n_{1},\left[n_{1} s\right]+1}(J)\right) \\
W_{n_{2}}^{*}(J)(s, u) & =n_{2}^{1 / 2}\left(\sum_{i=1}^{\left[n_{2} s\right]} C_{n_{2} j}(J)(u)+\left(n_{2} s-\left[n_{2} s\right]\right) C_{n_{2},\left[n_{2} s\right]+1}(J)(u)\right) .
\end{aligned}
$$

By similar techniques as in Lemma 3.1 one can prove that the process $W_{n_{1}}(J)(s)$ converges weakly in uniform topology to a Gaussian process $W_{0}(J)(s)$ with trajectories a.s. in $\mathbf{C}_{1}$ with mean 0 and variance

$$
\begin{aligned}
& s\left[\int_{0}^{1} \int_{0}^{1} f_{1}^{2}(u) d\left(F^{(1)} \circ H^{-1}\right)(u)\right. \\
& \left.\quad+2 \sum_{p \geqq 1} \int_{0}^{1} \int_{0}^{1} f_{1}(u) f_{1}(v) d\left(G_{p}^{(1)}\left(H^{-1}(u), H^{-1}(v)\right)\right)\right]
\end{aligned}
$$

and $W_{n_{2}}^{*}(J)(s, u)$ converges weakly in uniform topology to a Gaussian process $W_{0}^{*}(J)(s, u)$ with trajectories a.s. in $\mathbf{C}_{1}^{*}$ with mean 0 and variance

$$
\begin{aligned}
& s u\left[\int_{0}^{1} f_{2}^{2}(u) d\left(F^{(2)} \circ H^{-1}\right)(u)\right. \\
& \left.\quad+2 \sum_{p \geqq 1} \int_{0}^{1} \int_{0}^{1} f_{2}(u) f_{2}(v) d\left(G_{p}^{(2)}\left(H^{-1}(u), H^{-1}(v)\right)\right)\right] .
\end{aligned}
$$

From this and following Lemma 3.2, it is easy to prove that $V_{n}^{*}(J)$ converges in law to the normal distribution with mean 0 and variance $\widetilde{\sigma}_{J}\left(\left\{\widehat{G}_{p}^{(l)}\right\}\right)$ where $\widetilde{\sigma}_{J}\left(\left\{\widehat{G}_{p}^{(l)}\right\}\right)$ is defined in (4.5) and $V_{n}^{*}(J)$ is a random variable defined by

$$
\begin{aligned}
V_{n}^{*}(J)=n^{1 / 2}( & \int_{-\infty}^{+\infty} J\left(\widehat{F}_{n}(x)\right) d\left(\widehat{F}_{n}^{(1)}(x)-F_{n}^{(1)}(x)\right) \\
& \left.+\int_{-\infty}^{+\infty} J^{\prime}\left(\widehat{F}_{n}(x)\right)\left(\widehat{F}_{n}(x)-F_{n}(x)\right) d F_{n}^{(1)}(x)\right) .
\end{aligned}
$$

Since $\mathcal{S}_{n}^{*}(J)=V_{n}^{*}(J)+U_{n}(J)$ where $\mathbf{E}\left(U_{n}(J)\right)^{2}=O\left(n^{-1 / 2}\right)$ we prove Theorem 4.1 following the line of argument in the proof of Theorem 3.1.

\section{REFERENCES}

[1] S. BAlachefF AND G. Dupont, Normalité asymptotique des processus empiriques tronqués et des processus de rang, Lect. Notes Math., 821 (1980), pp. 19-46.

[2] P. Billingsley, Convergence of Probability Measures, Wiley, New York, 1968.

[3] H. Chernoff ANd I. R. Savage, Asymptotic normality and efficiency of certain nonparametric test statistics, Ann. Math. Statist., 29 (1958), pp. 972-994.

[4] M. Denker and U. Rösler, Some contributions to Chernoff-Savage theorems, Statist. and Decision, 3 (1985), pp. 49-75. 
[5] P. Doukhan and F. Portal, Principe d'invariance faible pour la fonction de répartition empirique dans un cadre multidimensionnel et mélangeant, Probab. Math. Statist., 8 (1987), pp. 117-132.

[6] V. DuPAČ AND J. HÁJEK, Asymptotic normality of simple linear rank statistics under alternative II, Ann. Math. Statist., 40 (1969), pp. 1992-2017.

[7] T. R. FEARs AND K. L. Mehra, Weak convergence of a two-sample empirical process and a Chernoff-Savage theorem for $\varphi$-mixing sequences, Ann. Statist., 2 (1974), pp. 586-596.

[8] Z. Govindarajulu, L. Le Cam, and M. Raghavachari, Generalizations of theorems of Chernoff and Savage on the asymptotic normality of test statistics- In: Proceedings of the Fifth Berkeley Symposium on Mathematical Statistics and Probability. V. I. Berkeley-Los Angeles: Univ. California Press, 1967, pp. 609-638.

[9] J. HÁJEK, Asymptotic normality of simple linear rank statistics under alternatives, Ann. Math. Statist., 39 (1968), pp. 325-346.

[10] R. PYKE AND G. R. SHORACK, Weak convergence of a two-sample empirical process and a new approach to Chernoff-Savage theorems, Ann. Math. Statist., 39 (1968), N 3, pp. 755-771.

[11] C. S. Withers, Convergence of empirical processes of mixing r.v.'s on [0, 1], Ann. Statist., 3 (1975), pp. 1101-1108. 
Reproduced with permission of the copyright owner. Further reproduction prohibited without permission. 